\title{
Representaciones discursivas de lo indígena en Costa Rica: un análisis a través de la red social Facebook
}

\section{Discursive Representations of the Indigenous Peoples in Costa Rica: An Analysis Through the Social Network Facebook}

DOI 10.15517/rr.v99i2.39040

Guillermo González Campos ${ }^{1}$

${ }^{1}$ Sede del Atlántico, Universidad de Costa Rica, Costa Rica, gonzalezcampos@gmail.com ORCID https://orcid.org/0000-0001-8066-7769

Fecha de recepción: 15 de setiembre del 2019 Fecha de aceptación: 27 de mayo del 2020

\section{Resumen}

\section{Introducción}

Este artículo lleva a cabo una discusión crítica de los principales núcleos temáticos que gobiernan la producción del sentido en mensajes generados por la población costarricense no indígena en la red social Facebook con respecto a los pueblos indígenas del país.

Objetivo

El objetivo es identificar y analizar los discursos dominantes que, en la actualidad, gobiernan lo dicho sobre la población indígena en Costa Rica.

\section{Método}

Para tal efecto, y por medio de las técnicas propias de Corpus-assisted discourse studies, se recopilaron y analizaron comentarios hechos por personas a noticias que tratan asuntos indígenas.

Resultados

El análisis revela que el discurso sobre lo indígena en Costa Rica está determinado por cuatro núcleos de generación del sentido que se consideran perjudiciales para la representación social de este tipo de poblaciones.

\section{Conclusión}

Puede concluirse que, en efecto, hay una integración a nivel del discurso de lo indígena dentro del imaginario de identidad costarricense. Pero esta imagen de lo indígena es la asimilación de un discurso creado desde la alteridad y, por lo tanto, guarda las herencias simbólicas de la ideología colonizadora que la creó.

Palabras clave: Pueblos originarios, Identidad nacional, Medios sociales, Ideología, Análisis del discurso. 


\begin{abstract}
\end{abstract}
Introduction

This article critically discusses the main thematic cores in the discourses generated on Facebook by non-indigenous Costa Ricans about indigenous communities.

Objective

The objective is to identify and analyze the dominant discourses about this population in Costa Rica.

Method

To this purpose and using the Corpus-assisted discourse techniques, comments made by nonindigenous individuals to Facebook news about indigenous issues were collected and analyzed.

Results

The analysis shows that the discourse about indigenous issues in Costa Rica is influenced by four cores of speaker intentionality that are considered prejudicial to the social representation of indigenous population.

\title{
Conclusion
}

It can be concluded that, in fact, there is an integration of indigenous culture at a discourse level within the imaginary of Costa Rican identity; however, this image is the assimilation of a discourse built from otherness. Therefore, it keeps the symbolic inheritance from the colonization ideology that created it.

Keywords: Native peoples, National identity, Social media, Ideology, Discourse analysis.

\section{Introducción}

En las últimas tres décadas, en los medios académicos costarricenses, ha habido un amplio consenso en sostener que el discurso hegemónico sobre la identidad nacional se ha fundado sobre un modelo ideológico, cuya principal presunción es creer que el país está conformado esencialmente por gente «blanca» ${ }^{1}$. Se trata, en concreto, de un discurso racista defensor de una supuesta identidad basada en rasgos biológicos y culturales de ascendencia europea. Al partir de dicho supuesto, este discurso ha excluido del imaginario nacional cualquier representación que no concuerde de forma explícita con esta idea. Esto ha provocado la

\footnotetext{
${ }^{1}$ La bibliografía al respecto es inmensa y abarca diversas disciplinas de las Ciencias Sociales y las Letras costarricenses. Escapa a las pretensiones de este trabajo ofrecer un recuento exhaustivo de esta. Sin embargo, no pueden dejar de citarse algunas obras que resultan paradigmáticas dentro de dicho conjunto bibliográfico. A nivel literario, la discusión arranca con las obras de Ovares, Santander y Carballo (1993) y Quesada Soto (1998). Desde la filosofía, existe el acercamiento hecho por Giglioli (1996) y el amplio trabajo de Jiménez (2005). A nivel histórico, fueron pioneras las investigaciones de Palmer (1996) y Acuña (2002). Para una revisión más reciente de dicha cuestión, consúltense el trabajo de Pacheco Hernández (2013).
} 
marginación simbólica y material de diversas poblaciones, en particular los indígenas, los afrocostarricenses y, en épocas más recientes, los migrantes de origen nicaragüense.

Bajo dicho marco interpretativo, queda claro que el elemento indígena, tema que aborda este trabajo, fue suprimido completamente del discurso identitario nacional. Bien lo demostró Soto Quirós (1998), quien, al estudiar las bases históricas de esta formulación enunciativa, no deja de señalar que, a finales del siglo XIX, los intelectuales costarricenses desaparecieron a los grupos indígenas por medio de la idea de que eran pocos, se encontraban en vías de extinción y, por ende, no podían tener ningún tipo de conexión o papel en la construcción de la nacionalidad.

Dicho proceso de exclusión, sin embargo, no deja de contrastar con lo ocurrido en otros países latinoamericanos, donde las culturas indígenas (o al menos, una construcción artificial o folclórica de estas) fueron incorporadas en la base discursiva de sus respectivas nacionalidades. ${ }^{2}$ Ello lo recuerda Martínez Hoyos $(2018$, 143), quien explica que «los independentistas latinoamericanos buscaron, como referente histórico, el pasado precolombino, como si el mundo de los criollos fuera heredero de los pueblos sometidos a los conquistadores del siglo XVI». Si bien el caso paradigmático es México y su tradición de fundamentar su nacionalidad simbólica en la cultura azteca, también pueden mencionarse como ejemplos a otras naciones. Tal es el caso de Chile, que instrumentaliza el elemento araucano como símbolo nacional, sobre todo por medio de la heroización del cacique Lautaro; o, incluso Uruguay, país cuyos ciudadanos se denominan «charrúas», gentilicio tomado directamente de la denominación de un conjunto de pueblos amerindios del Río de la Plata, los cuales, contradictoriamente, fueron exterminados durante el siglo XIX.

\footnotetext{
${ }^{2}$ Estas dos tendencias, integración o invisibilización de lo indígena en el discurso identitario, son dos de las estrategias discursivas que David Díaz $(2004,33)$ establece como elementales en el proceso simbólico de construcción de la nación en Latinoamérica. La tercera mencionada por este autor es el exterminio. En realidad, este última no es de carácter discursivo, sino una política de estado derivada de las concepciones ideológicas propaladas por medio del discurso, la cual no excluye, de ninguna manera, la presencia de las otras dos. En este sentido, cabe destacar que, como explica Martínez Hoyos (2018), en no pocos casos, se cayó en contradicciones flagrantes entre los hechos y el discurso. Por dar un ejemplo, por un lado, se idealizó completamente el pasado incaico, pero, al mismo tiempo, se generó un desprecio y marginación de los actuales indígenas peruanos.
} 
No obstante, la invisibilización o negación de lo indígena como elemento identitario nacional no es un proceso exento de contradicciones, como bien lo recuerda Camacho Nassar (1998). Para este autor, los indígenas sí han sido incorporados ocasionalmente en los discursos identitarios de Costa Rica, en procesos discursivos bastante similares a los mencionados anteriormente para otros países latinoamericanos. Es decir, se cuentan como integrantes de un pasado idealizado que da origen a determinados valores y actitudes típicas de la población actual. En palabras suyas, los indígenas conforman, para el discurso hegemónico nacional, una imagen ambivalente o paradójica:

\begin{abstract}
aún negados, calificados de inexistentes, replegados en las peores tierras y en las más abyectas condiciones de pobreza, enfermedad y exclusión social, los indios de Costa Rica están presentes a lo largo y ancho del discurso de la identidad nacional. Esta paradoja que por una parte postula que un grupo no existe o existe tan escasamente que no es significativo y, por otra, deriva de este grupo valores que supuestamente comparten millones de habitantes, por lo demás blancos por definición más que por realidad, permite explicar el uso perverso de la ideología por parte de los grupos dominantes y uno de los sustentos aberrantes de una identidad nacional construida sobre la más absurda de las fabulaciones. (Camacho Nassar 1998, 312).
\end{abstract}

Hay buenas razones para pensar que, en los últimos tiempos, este tipo de imágenes y discursos se ha ido propagando de forma mayoritaria en la población costarricense de origen no indígena. En efecto, han emergido, por ejemplo, figuras aborígenes que han sido promovidas al estatus de «héroes nacionales». El caso típico por antonomasia es Pablo Presbere quien, en las últimas décadas, se ha convertido en un personaje cuya construcción discursiva reivindica su espíritu rebelde y «libertario» como una forma de proteger a los pueblos indígenas y resistir el embate de la conquista española. Es una construcción que, por otro lado, no deja de tener vicios evidentes de anacronismo. Presbere, en todo caso, constituye un personaje muy complejo e interesante cuya construcción en el imaginario actual debe abordarse en un futuro mediante una investigación exhaustiva y particular.

Otra situación que ilustra muy bien esta propagación de discursos sobre cierto origen indígena de la identidad costarricense, son los intentos por «indigenizar» términos y expresiones lingüísticas utilizadas por los habitantes del Valle Central. El ejemplo más significativo es la propuesta del cantautor Dionisio Cabal (2008), quien propuso que el 
nombre mismo del país es de origen huetar, pues proviene de un supuesto «co-taque-rrique». Esta propuesta, junto con otra del mismo autor (Cabal 2016) que sugería un mismo origen huetar para la interjección «upe», tuvieron amplísima difusión y comentarios en redes sociales, y debieron ser desmentidas recientemente por Quesada Pacheco (2017). En este caso, lo relevante no es el desatino de la propuesta, sino entender cómo esta se corresponde con una necesidad ideológica de buscar, en este caso específico mediante una falsa etimología, un referente indígena para el pasado nacional.

En fin, parece claro que hoy día lo indígena no se encuentra tan excluido del discurso identitario costarricense. La población hegemónica del país, de una u otra forma, ha ido asumiendo ciertas concepciones sobre dichas poblaciones y las vienen interiorizando y manifestando en diversos medios. Representaciones indígenas alternativas, por lo tanto, han venido ganando terreno en la discursividad social costarricense.

Partiendo de dicha idea, en este trabajo se propuso realizar un acercamiento analítico de estas manifestaciones con tal de entender mejor el papel que cumplen en el actual imaginario nacional. En otras palabras, interesa aquí develar el conjunto de juicios y procesos discursivos que manifiesta la población costarricense no indígena sobre dichos pueblos, en aras de determinar cuáles son los discursos dominantes que gobiernan la producción de lo dicho a este respecto.

Para lograr tal cometido, este trabajo presenta los resultados de una investigación de tipo exploratorio, realizada durante los años 2015 y 2016 en la red social denominada Facebook. El foco de dicha investigación fueron los comentarios hechos por personas a noticias que tratan asuntos indígenas, y que fueron publicadas en las respectivas páginas de dichos medios. Como se sabe, los periódicos suelen tener una página oficial de Facebook en la que publican (o «postean», como suele decirse de forma coloquial) el enlace a noticias albergadas en sus respectivas páginas de Internet. Una vez publicado el enlace, las personas pueden hacer diversos comentarios a dicha notica. Estos comentarios fueron justamente el dato primario que se recopiló para hacer un análisis que permitiera comprender el papel simbólico que lo indígena cumple actualmente en el mundo identitario nacional y conocer así si este se encuentra signado por la exclusión, como ha sido tradicionalmente asumido; o si, por el 
contrario, ahora juega algún otro papel dentro de la construcción simbólica de la identidad nacional. Como se verá, los datos apuntan a una tendencia del segundo de los casos.

\section{Algunas consideraciones teóricas y metodológicas}

La investigación que sirvió de base para la redacción de este trabajo se enmarca en las técnicas propias del Análisis del Discurso, el cual es entendido aquí como un ámbito de estudio que aborda, desde diversas metodologías y teorías, un conjunto sistemático de expresiones lingüísticas dichas por un grupo social, las cuales tienen un significado y producen un efecto dentro de un determinado contexto social y cultural. ${ }^{3}$

Dichos estudios son muy amplios, diversos y complejos. Aquí se tomará como punto de partida la propuesta de Norman Fairclough (1992), quien ha dividido los diversos trabajos hechos dentro del Análisis del Discurso en dos grandes tipos: los críticos y los empíricos (no críticos). Para el caso particular de este trabajo, se ha asumido una posición crítica. Desde esta perspectiva, el Análisis del Discurso asume como fin primordial el estudio del lenguaje en tanto práctica social $\mathrm{y}$, por ende, pretende poner de manifiesto la opacidad y el encubrimiento de diversas relaciones de dominación. Dentro de dicha tendencia, se parte de la idea de que las prácticas discursivas tienen efectos ideológicos; es decir, ayudan a producir y reproducir los abusos de poder y la desigualdad que se da en los distintos grupos humanos. ${ }^{4}$ Por tanto, la posición que se adoptará con respecto a los comentarios mencionados anteriormente, no será de tipo descriptivo; antes bien, se propone abordarlos de forma valorativa a fin de señalar prácticas discursivas inadecuadas o perniciosas.

Para la recopilación y el procesamiento de los datos, este trabajo utilizó las técnicas propias de los Corpus-assisted discourse studies (CADS), los cuales estudian el discurso utilizando las técnicas informáticas desarrolladas por la Lingüística de Corpus 5 . Esto implica esencialmente recoger diversas muestras lingüísticas e integrarlas en un corpus electrónico a

\footnotetext{
${ }^{3}$ Para más detalles sobre dicha disciplina, véase la entrada correspondiente a dicha expresión en el diccionario elaborado Patrick Charaudeau y Dominique Maingueneau (2005).

${ }^{4}$ Como introducción a la definición, la historia, los métodos y las disciplinas involucradas en el análisis del discurso, los dos volúmenes editados por Van Dijk (2000a) y (2000b) son esenciales.

${ }^{5}$ Aquellos que desconozcan los procesos propios de la Lingüística de Corpus, pueden consultar el libro de Parodi (2010), que constituye una excelente introducción a dicha disciplina.
} 
fin de someterlas a algún tipo de análisis ${ }^{6}$. Esta técnica es especialmente productiva en el trabajo con materiales procedentes de Internet y cuya digitalización ya ha sido hecha, pues permite recopilar y manejar grandes cantidades de texto. Mancera y Pano (2014), de hecho, han señalado que este tipo de técnica es altamente productiva para analizar diversas propiedades de tipo lingüístico de elocuciones tomadas de redes sociales pues, debido a diversos condicionantes situacionales, los usuarios de medios informáticos como Facebook o Twitter tienden a utilizar una modalidad coloquial y espontánea típica de la inmediatez comunicativa. A nivel del discurso, esto significa que dichas manifestaciones recogen a un nivel primario las bases ideológicas fundamentales que animan la producción del discurso con respecto a un determinado tema (en palabras burdas, puede decirse que la gente pone en los comentarios «lo primero que se le viene a la cabeza»).

El corpus de la investigación estuvo conformado por 378 comentarios de noticias publicadas en Facebook, en las páginas de tres medios de publicación diaria: La Nación, La Prensa Libre y Diario Extra. Dicha selección obedeció a criterios de conveniencia personal y accesibilidad. En todos los casos, se trató de comentarios hechos durante los años 2015 y 2016 a textos de periodismo informativo cuya temática giraba en torno a situaciones en la que estuvieran implicados, de alguna forma, indígenas costarricenses. Todos los comentarios fueron integrados en una base de datos electrónica para su posterior análisis.

Debido a que este trabajo no aborda ningún tipo de propiedad gramatical de la lengua, se obvió utilizar algún proceso de marcaje estructural o anotación lingüística de los enunciados. Simplemente, se utilizó como método básico la obtención de concordancias o palabras clave en contexto (key word in context), así como colocaciones, las cuales permiten conocer la coaparición de palabras en un mismo segmento textual y, por ende, entender qué elementos se asocian mayoritariamente a una determinada noción. En nuestro caso particular, esto permitió comprender qué palabras se asocian más frecuentemente a los indígenas en el corpus recogido.

\footnotetext{
${ }^{6}$ Para más detalles sobre las diferentes facetas de este tipo de metodología, véase el volumen compilado por Baker y McEnery (2015).
}

\section{(cc) EY-NC-ND}

Esta obra está bajo una Licencia Creative Commons Atribución-NoComercial-SinDerivadas 4.0 Internacional. 
Dicho procedimiento permitió definir la representación discursiva de los indígenas en el corpus seleccionado. Cabe hacer algunas aclaraciones preliminares con respecto a esta noción, pues se trata de un concepto que no está exento de polémica. Como indica Matus (2015), muchos suelen usarlo en sentido lato para expresar la manera por la cual un determinado concepto es mostrado o expresado en un texto. Dicha manera de proceder no parece la más adecuada desde un punto de vista técnico. Otros suelen asociarlo a la Teoría de la Representaciones Sociales de Moscovici. Sin embargo, hay que tener presente que esta teoría se refiere más bien a procesos de conciencia, ya que se enmarca en el quehacer propio de la Psicología Social; es decir, la representación en esta teoría es de orden cognitivo, no discursivo.

Para solucionar dichos problemas, Matus (2015) propone entender las representaciones discursivas a partir de su dimensión material, es decir, a partir de los textos (ya sean orales o escritos); y como una forma de acceder, por medio de la inferencia, a la construcción mental hecha por el sujeto hablante. Así, de acuerdo con sus planteamientos, puede brindarse la siguiente definición: «se postula que las representaciones discursivas son las expresiones materiales (textuales) de las referencias (representaciones) que la conciencia de los hablantes/oyentes elaboran sobre el/un mundo. Vistas de este modo, las representaciones discursivas existen siempre en el texto, aunque den cuenta de una realidad ideal. Esa realidad puede ser, como se ha visto, relativa al macro-nivel de la cultura o mundo de sentido de los hablantes (p.e. la ideología), tanto como a un simple objeto abstracto (p.e. ayer) o a un elemento del entorno material (p.e. mesa)» (Matus 2015, 5).

Así pues, este trabajo presenta los resultados de una investigación hecha con fundamento en la recopilación de un corpus electrónico de datos linguísticos, conformado por comentarios tomados de la red social Facebook. La intención fue practicarles un análisis crítico del discurso que permitiera comprender qué se dice sobre los indígenas costarricenses en dichos espacios comunicativos y así entender si la figura del indígena juega, en la actualidad, algún papel relevante dentro de las dinámicas discursivas de índole identitaria en Costa Rica. 


\section{Identidad nacional $y$ discurso sobre lo indígena en Costa Rica: primeros resultados $\mathbf{y}$ valoraciones}

En este apartado, se presentarán y discutirán los principales hallazgos obtenidos durante el proceso investigativo. Para organizar mejor la presentación de los datos, esta sección se subdividirá en cuatro partes, cada una de las cuales abordará un fenómeno discursivo diferente relacionado con la forma como se representa a los indígenas en los comentarios de Facebook. En efecto, tras realizar el análisis explicado antes, pudo comprobarse que el discurso sobre lo indígena en Costa Rica está determinado por cuatro núcleos de generación del sentido que, si bien se encuentran interrelacionados, son susceptibles de ser descritos y valorados de forma independiente. Todos ellos, sin embargo, constituyen representaciones discursivas heredadas de la concepción europea sobre dichos grupos humanos, tal y como se verá más adelante. Dichos núcleos son los siguientes:

a) La idea de que los indígenas constituyen una colectividad abstracta que es susceptible de ser apropiada mediante el posesivo «nuestro».

b) La suposición de que los indígenas conforman el pasado de la nación y, por ello, son los antepasados de los actuales costarricenses.

c) La percepción, derivada de la concepción anterior, de que los indígenas son los «auténticos costarricenses».

d) El paradigma discursivo que defiende que los indígenas viven en armonía con la naturaleza.

Cada una de estas articulaciones discursivas será debidamente descrita y criticada, exponiendo la base prejuiciosa de su sustento ideológico e ilustrada con ejemplos de comentarios que reflejan la cuestión que es objeto de análisis. Debe tenerse en cuenta, sin embargo, que los ejemplos incluidos son casos meramente ilustrativos tomados del corpus recopilado. Desde luego, en el conjunto textual total, hay gran cantidad de ejemplos que manifiestan las mismas ideas y consignarlos todos es imposible por razones de espacio. Además, sería improductivo, pues, como se ha dicho, a grandes rasgos expresan, con distintas palabras, las mismas concepciones. 
Al consignar los ejemplos, se seguirá la propuesta hecha por Mancera y Pano (2014) de suprimir los nombres de los autores de los comentarios, con el fin de proteger la identidad de sus redactores. Hay que tener presente que las redes sociales son un entramado complejo donde lo público y lo privado se aúnan y se mezclan, a su vez, con construcciones de identidades digitales que, en ciertas ocasiones, difieren notoriamente de las identidades físicas. Además, hay que tener presente que muchas personas no son conscientes de las implicaciones que conlleva el ejercicio de opinar en una red social. Así, aunque publicar algo en Facebook constituye una actividad pública, muchos suponen que sus manifestaciones son de carácter restringido y, en consecuencia, opinan bajo dicha dinámica. De cualquier manera, los nombres son irrelevantes en este caso particular. Recuérdese que el discurso manifestado no se corresponde a una concepción específica de una persona, sino que tiene que ver más bien con producciones sociales de sentido. Se trata de maneras de ver el mundo colectivas, no individuales.

\section{Homogenización y apropiación del mundo indígena}

La primera situación que salta a la vista cuando se hace un Análisis del Discurso de los comentarios vertidos en Facebook sobre las noticias relativas a indígenas costarricenses, es el hecho de que estos son vistos de una forma completamente general y homogenizada. A grandes rasgos puede afirmarse que, en los comentarios, «lo indígena» es una construcción abstracta, algo vaga y etérea; que no tiene ningún tipo de relación con los referentes reales. Gran parte de esto se debe obviamente al desconocimiento y es el origen mismo de la categoría el factor clave para entender dicha práctica discursiva. Tal y como explica Martínez Hoyos $(2018,21)$, la «invención del indio» es una consecuencia directa de la colonización europea y un producto del pensamiento occidental y sus prejuicios. De esta forma, la categoría de indígena no es más que una forma, bastante simplista, de referirse a un conjunto enorme y diverso de pueblos, idiomas y culturas.

Cabe preguntarse por qué existe una categoría para referirse a un conglomerado tan vasto y plural en su integración. La respuesta a esta pregunta tiene que ver, como se dijo, con el origen ideológico de la palabra. La categoría de indígena es básicamente una noción creada 
dentro de la lógica de la alteridad. Esto significa que no se constituye a partir de un grupo de características que le sean inherentes a estos pueblos, sino a partir de la negación u oposición de estos con respecto a otros (en este caso, los integrantes de la civilización occidental). Por eso, es una construcción creada desde el pensamiento eurocentrista (representado en nuestras naciones por los autodefinidos como «blancos»).

Ser indígena es ser la otredad, es no ser o no poseer las características que definen al «sí mismo» parlante (el ciudadano europeo u occidental, o sea, el «blanco»), el cual, está demás aclarar, es precisamente quien crea la categoría. De ahí que no haya elementos propios que definan la «indigeneidad». Lo indígena, en tanto elemento identitario, es una mera invención. Resulta difícil, por no decir imposible, suponer que existen rasgos definitorios para esta categoría que tengan alcance continental y que justifiquen la inclusión de centenares de pueblos dentro de esta ${ }^{7}$.

Para el caso particular de Costa Rica, cabe señalar que hablar de «indígenas» es una herencia del pensamiento colonialista antes mencionado y, por ende, constituye un claro proceso de simplificación de una realidad diversa y compleja. No puede, de ninguna forma, pensarse que los chorotegas tengan las mismas condiciones sociales o culturales que los bribris de Talamanca. No hay manera de equiparar ambos grupos.

En el país existe muchos pueblos indígenas, todos con realidades culturales y sociales disímiles. Cada pueblo es distinto y merece el reconocimiento de su diferencia. Incluso dentro de un mismo pueblo indígena hay disparidades. Por ejemplo, los cabécares que habitan en Chirripó poseen condiciones culturales y sociales muy diferentes de sus parientes de Ujarrás. Sin embargo, todo esto es ignorado por completo a nivel discursivo (cabe destacar, que también a nivel de políticas institucionales). En general, los comentarios hechos en Facebook revelan que, a nivel enunciativo, existen los indígenas en tanto categoría englobante y nada más. Desde este punto de vista, no puede dejarse de señalar que es sumamente lamentable

\footnotetext{
${ }^{7}$ Algunos movimientos políticos, sin embargo, suelen señalar que a los pueblos originarios de América los hermana la lucha política que deben acometer para defenderse de los abusos infringidos por la población «blanca». Se trata de intentos recientes de redefinir lo indígena desde perspectivas que no tengan como punto de partida la herencia colonial europea. Para más detalles, véase el artículo publicado por de la Cadena y Starn (2009), el cual hace un repaso histórico y conceptual de la noción de «indigeneidad» y los diversos intentos actuales de resignificación del término.
}

\section{(cc) BY-NC-ND}

Esta obra está bajo una Licencia Creative Commons Atribución-NoComercial-SinDerivadas 4.0 Internacional. 
que, por lo regular, el costarricense promedio sea capaz de distinguir un alemán de un italiano, pero no un malécu de un cabécar.

Un buen ejemplo que nos muestra este proceso de simplificación discursiva lo encontramos en el enunciado que acompaña el «posteo» de la siguiente noticia (véase Figura 1), la cual anuncia la celebración de un evento en la comunidad boruca de Rey Curré:

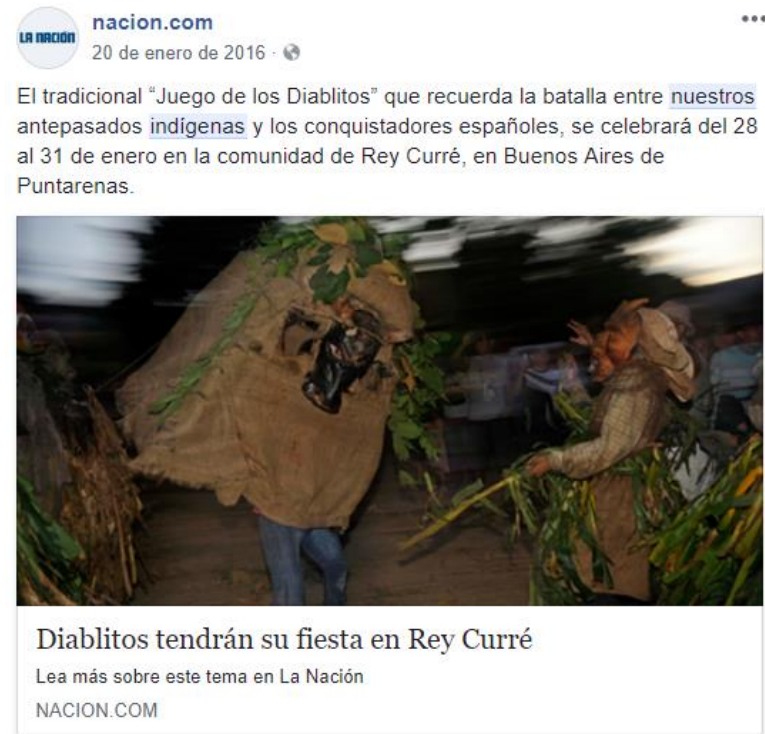

Figura 1. Noticia publicada en Facebook Fuente: Captura de Facebook.

Nótese que el texto periodístico es un anuncio de un evento muy específico: la Fiesta de los Diablitos, la cual es una actividad muy propia del pueblo boruca. De hecho, es una las prácticas culturales que más definen la identidad de este grupo étnico. A pesar de ello, el enunciador, al publicar la noticia, no inscribe el acontecimiento dentro de las particularidades de este pueblo costarricense y en lugar de ello, recurre a la categoría englobante, es decir, al término «indígena», el cual es calificado por medio del pronombre «nuestro» y el adjetivo «antepasados», rasgos que se comentarán más adelante. Claramente se aprecia el proceso discursivo del que se viene hablando: se reduce la especificidad cultural de un pueblo y se integra en una categoría general, desvinculándolo, de esta forma, de su muy particular contexto. 
Una típica consecuencia de esta forma de proceder es la práctica discursiva de suponer que los indígenas piensan, sienten, opinan y viven igual. La gente suele hacerse preguntas tales como «¿qué dicen los indígenas cuando...?», «¿cómo proceden los indígenas ante...?». Es como si supusieran que estos son una masa que piensa y actúa de forma coordinada y uniforme. No reconocen los puntos de vista individuales que existen, pues dos individuos de un mismo pueblo, aunque vivan en el mismo vecindario, no tienen por qué pensar o actuar de la misma forma. Así pues, estamos en presencia de un reduccionismo que favorece la constitución de estereotipos.

Ahora bien, los indígenas costarricenses no solo son homogenizados por el discurso dominante, negando su derecho a la diferencia; sino que, como se ve en la cita anterior, además son poseídos por el colectivo enunciador a través del uso del pronombre «nuestro». Así, se crea la expresión «nuestros indígenas», de amplísimo uso y extensión, que sirve como denominador común para designar a todos estos individuos. ¿Qué función exacta cumple el uso del pronombre posesivo en estos casos? Una posible explicación es que constituye una estrategia de nivel lingüístico para integrar al colectivo indígena, creado originalmente como una alteridad diferente del resto de los habitantes del país, dentro del espacio identitario nacional. En palabras más llanas, la categoría de indígena, debido al origen ideológico antes mencionado, no se asume como parte del conjunto mayoritario de la población costarricense y, por ello, solo puede ser asumida como parte integrante del colectivo nacional por medio de la posesión. ${ }^{8}$

Algunos ejemplos pueden clarificar mejor esta propuesta. Tal es el caso de la siguiente cita (véase Figura 2), que se enmarca en una situación crítica vivida a principios del año 2016, cuando un enorme contingente de migrantes, sobre todo cubanos, se quedaron varados en su viaje hacia los Estados Unidos:

\footnotetext{
${ }^{8}$ Sin embargo, nótese que solo con este tipo de población aplica el proceso de posesión. Siempre se dice «nuestros indígenas», nunca se dice «nuestros negros»o «nuestros chinos».
}

\section{(cc) EY-NC-ND}




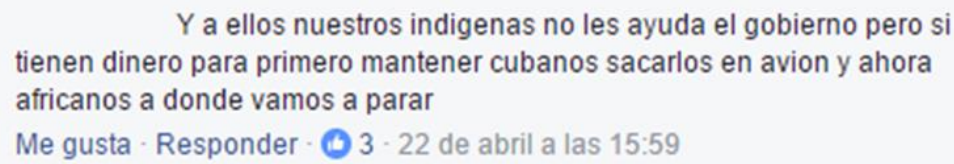

$Y$ a ellos nuestros indigenas no les ayuda el gobierno pero si tienen dinero para primero mantener cubanos sacarlos en avion y ahora africanos a donde vamos a parar

Me gusta - Responder - 3 - 22 de abril a las 15:59

Figura 2. Comentario emitido en Facebook

Fuente: Captura de Facebook.

Nótese que el enunciador, al comentar la noticia «Indígenas cabécares de Chirripó denuncian olvido del gobierno», opta por incluir a los indígenas dentro del colectivo nacional por medio del uso del pronombre «nuestro». Al hacerlo, queda claro que ellos sí merecen una ayuda estatal que no está llegando. Se evidencia, de forma abierta, el tono de reproche, pues la comparación con los cubanos y africanos detenidos en la frontera norte no es gratuita. Está claro que ellos, a diferencia de los indígenas, no son asumidos como parte del colectivo nacional y, por lo tanto, no debería ayudárseles. Esto puede verse con mucha más precisión en el siguiente comentario (Figura 3) dado en el mismo contexto, en el cual la comparación no se hace con migrantes que se dirigen hacia Estados Unidos, sino con los nicaragüenses, quienes, en los últimos años, se han convertido en la instancia de alteridad por antonomasia de Costa Rica:

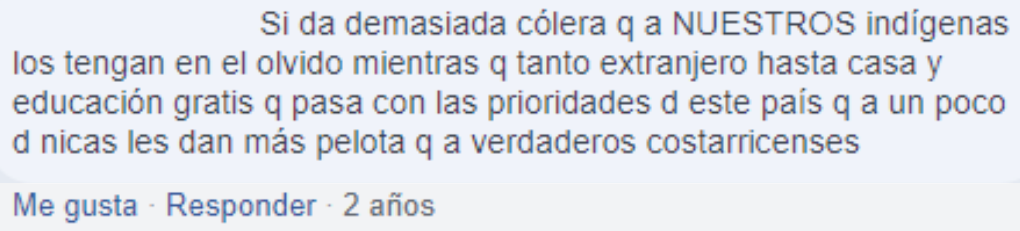

Figura 3. Comentario emitido en Facebook Fuente: Captura de Facebook.

La lógica discursiva se revela de forma clara: los nicaragüenses, al no ser costarricenses, no merecen ayuda de ningún tipo; los indígenas sí la merecen. Por ello, es claro que son entendidos como integrantes del colectivo nacional. El pronombre «nuestro», que está resaltado en el comentario, cumple en este sentido una función de inclusión dentro del colectivo nacional. Esto deja claro que a nivel del discurso se está haciendo uso de estrategias lingüística (en este caso la posesión) para incorporar el elemento indígena, que originalmente

\section{(cc) BY-NC-ND}

Esta obra está bajo una Licencia Creative Commons Atribución-NoComercial-SinDerivadas 4.0 Internacional. 
era entendido como una otredad, es decir, como un «no ser», dentro del conjunto identitario nacional. Entonces se da una identificación, al menos a nivel del discurso, con dichas poblaciones. Al respecto, puede considerarse la siguiente cita (Figura 4) que comenta un hecho de agresión sufrido por unos indígenas:

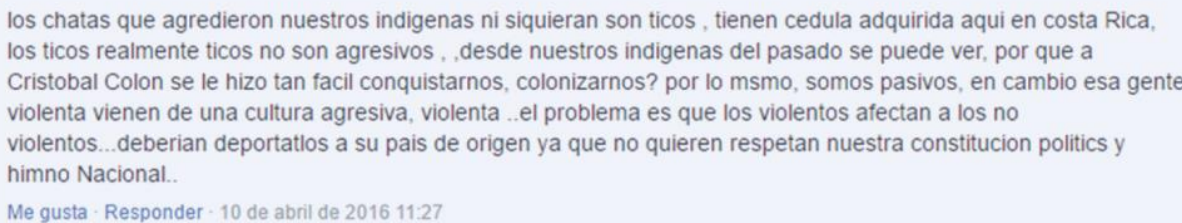

Figura 4. Comentario emitido en Facebook Fuente: Captura de Facebook.

Aquí, el proceso discursivo de integración de lo indígena en la nacionalidad costarricense es mucho más evidente. Se notan en la cita las dos características que se han señalado: los indígenas son mencionados desde su generalidad, pues no se especifica a qué pueblo pertenecen, y se determinan por medio del pronombre posesivo «nuestros». Ahora bien, los agresores, en este caso, son denominados «chatas» ${ }^{9}$ e implícitamente asimilados a nicaragüenses (nótese que propone la deportación como una solución para acabar con ellos). Si bien la dinámica categorial es compleja, es claro que los así llamados «chatas»son excluidos del conjunto identitario nacional por su carácter violento. No debe olvidarse que, en Costa Rica, desde los inicios de la construcción simbólica de la nación, la paz es parte importantísima del sistema axiológico nacional.

Los «realmente ticos» son gente pacífica. Quedan fuera de esta categoría, por tanto, quienes no posean estos rasgos (tradicionalmente, los nicaragüenses, a quienes el discurso xenófobo siempre tilda de violentos). Lo interesante acá es que el carácter sosegado del tico es puesto como una herencia indígena. Ello confirma el proceso de inscripción de los

\footnotetext{
${ }^{9}$ En Costa Rica, a nivel popular, suele denominarse «chatas» a ciertos jóvenes urbanos que se caracterizan por vestir según cánones relacionados con la moda propagada por los videos y cantantes del género musical denominado «reguetón». En el imaginario nacional, se considera, de forma estereotípica, que todos ellos son drogadictos y delincuentes. Es una categoría social de exclusión que debe estudiarse a nivel del discurso con mayor profundidad.
}

\section{(cc) BY-NC-ND}

Esta obra está bajo una Licencia Creative Commons Atribución-NoComercial-SinDerivadas 4.0 Internacional. 
indígenas dentro del conglomerado identitario nacional, pues son vistos como el origen de uno de los valores determinantes del «ser nacional». La afinidad del hablante con los indígenas termina siendo total cuando se ubica a sí mismo y sus congéneres (indígenas incluidos) como una víctima más de la conquista española, lo cual hace a través del uso del enclítico pronominal «nos»: «se le hizo tan facil conquistarnos...» (sin tilde en el original).

En conclusión, en los comentarios de Facebook analizados, hay suficiente evidencia de que, a nivel del discurso, lo indígena está siendo incorporado dentro de espacio identitario nacional. Sin embargo, esta inclusión sigue manteniendo los vicios conceptuales que derivan de la creación misma del término, el cual es básicamente una designación creada desde el pensamiento occidental para definir una alteridad cuya diversidad no puede o no quiere entender. En consecuencia, se genera cierta contradicción lógica que se resuelve, en el discurso, por medio del mecanismo lingüístico de la posesión. De esta forma, se crea la categoría general e inclusiva de «nuestros indígenas».

\section{La metáfora articuladora: los indígenas como «raíces»}

En la semántica tradicional, cuya última raigambre es el pensamiento aristotélico, se parte de la idea de que las metáforas constituyen «desvíos» de sentido de la literalidad, la cual era considerada como una constante en el uso lingüístico diario. Desde esta perspectiva, la utilización más común de las palabras entrevé un proceso lógico de apego a su denotación más precisa. Sin embargo, Lakoff y Johnson (1991) han propuesto la sugestiva teoría de que las metáforas son más comunes de lo que se pensaba y que gran parte de nuestro pensamiento se encuentra determinado por estas; además, no poseen solo un carácter literario, sino también cognitivo. Estas metáforas conceptuales, como ellos las llaman, sirven de base para referirse a diversas experiencias del mundo a través de esquemas idealizados cuya función última es facilitar el entendimiento conectando un concepto poco conocido o indeterminado con otro mejor conocido o más preciso. Así, por ejemplo, una expresión como «Nuestra relación ha entrado en un callejón sin salida», refleja la existencia de una metáfora conceptual que define las relaciones sentimentales, de carácter abstracto, mediante un hecho concreto, en este caso, una travesía. Así se define la metáfora de que EL AMOR ES UN VIAJE. 
Un Análisis del Discurso del corpus de mensajes, obtenido de los comentarios hechos en Facebook sobre los indígenas, posibilita identificar una metáfora conceptual sumamente reiterada, la cual permite comprender muy bien cuál es la percepción y sentir que la población costarricense no indígena posee con respecto a los indígenas. Dicha metáfora puede expresarse en la expresión LOS INDÍGENAS SON NUESTRAS RAÍCES. En la gran mayoría de los casos, esta equivalencia se manifiesta de forma explícita, como puede verse en la siguiente cita (Figura 5):

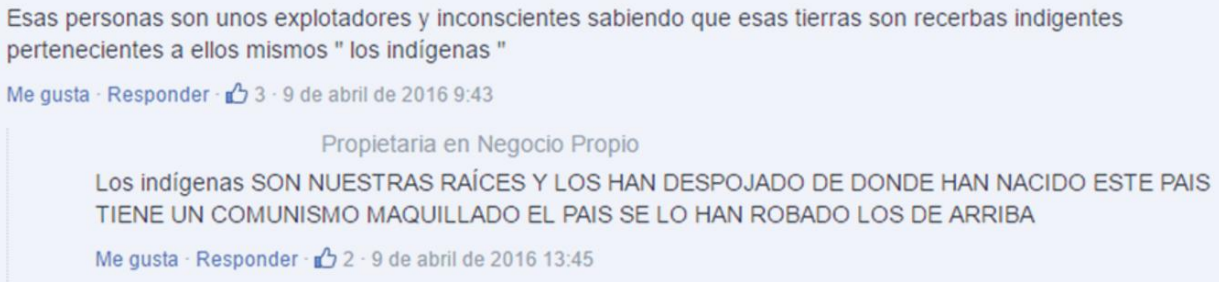

Figura 5. Comentarios emitidos en Facebook Fuente: Captura de Facebook.

Dejando de lado algunas situaciones que se salen del presente análisis, como el uso muy sui generis del término «comunismo», hay en estos mensajes, un proceso de indignación típico de los comentarios de Facebook ${ }^{10}$, enfocado en el despojo de tierras sufrido por los indígenas, el cual es un problema endémico que estos grupos humanos padecen en Latinoamérica. La metáfora se hace presente en el marco de un proceso argumentativo: a criterio del segundo enunciador presente en la cita, es injusto robarles la tierra a los indígenas porque estos son las «raíces», es decir, el origen del país. Está claro que se piensa aquí que su derecho a la tierra se fundamenta en el principio legal de Pior in tempore, potior in iure, lo cual nos permite comprender la dinámica ideológica que se esconde tras el establecimiento de la metáfora conceptual antes aludida.

\footnotetext{
${ }^{10} \mathrm{Si}$ bien este es un hecho que se sale de los límites del presente trabajo, no puede dejarse de mencionar que, en Facebook, los comentarios que manifiestan indignación sobre un hecho son, a todas luces, mayoritarios. La gente tiende a comentar más los sucesos negativos y, por ende, las notas relativas a estos tienden a viralizarse con mucha mayor rapidez que las «buenas noticias».
}

\section{(cc) EY-NC-ND}

Esta obra está bajo una Licencia Creative Commons Atribución-NoComercial-SinDerivadas 4.0 Internacional. 
La raíz es el primer órgano que se desarrolla en la planta, es el origen de toda ella. La raíz se entiende, entonces, como la parte primigenia que, por ramificación y desarrollo, va generando otros elementos. Cuando se dice entonces que «los indígenas son nuestra raíz», se está suponiendo que ellos constituyen los «antepasados» de los costarricenses, palabra que fue utilizada en el primer fragmento de texto citado en la sección anterior y que puede apreciarse también en uno de los comentarios que se incluyen a continuación (Figura 6):

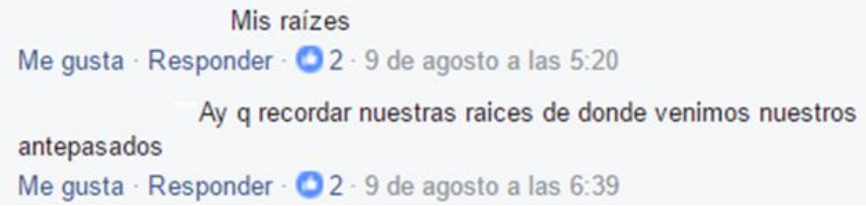

Figura 6. Comentario emitido en Facebook Fuente: Captura de Facebook.

Hay, en esta consideración, dos aspectos importantes por discutir, ambos de tipo ideológico. El primero de ellos es el origen y fundamento sobre esta idea de ver en los indígenas los «ancestros» de los costarricenses (la cual, desde luego, no tiene ningún fundamento real). Desde un punto de vista discursivo, se trata sin lugar a duda, de un mecanismo cuyo fin último es evitar asumir responsabilidades históricas lo cual, de acuerdo con Martínez Hoyos, surgió dentro de las comunidades criollas de América tras la independencia como una forma de desacreditar a los españoles y el bando realista que los apoyaba: «Los criollos, pese a su origen español, ensalzan al indio como fuente de la nacionalidad. [...] Esta actitud implicaba un uso muy selectivo del pasado. Así, mientras culpaban al "coloniaje" de todos los males, los criollos corrían un tupido velo sobre su propio papel como explotadores de indígenas en los tres siglos del virreinato. Es más, en una invención de sus raíces históricas, se presentaron ellos mismos como descendientes de los pueblos precolombinos, como si sus ascendientes no hubieran llegado del otro lado del Atlántico» (Martínez Hoyos 2018, 144).

Adolfo Constenla (2004), al analizar la presencia de este discurso en Costa Rica, ha sido sumamente crítico con estas ideas. Para él, hablar de «nuestras raíces indígenas», es básicamente una estrategia de ocultamiento de la herencia hispánica y una forma de eludir 
las responsabilidades de tipo histórico que las poblaciones no indígenas tienen para con aquellos que sí son indígenas, lo cual no coadyuva en nada al mantenimiento de sus realidades culturales. Desde su punto de vista, es falso que exista en Costa Rica una «cultura mestiza» en el sentido exacto del término, pues la cultura hegemónica es mayoritariamente de origen occidental: «La persona habla castellano y vive la civilización europeo-occidental, pero en la oratoria se declara indoamericana, sin advertir que sus "profundas raíces indígenas" no tienen reflejo en su vida práctica. Esas "profundas raíces" existen en la conducta retórica, no en la conducta real. Tal identificación tiene además otra utilidad porque nos permite a los miembros de la etnia continuadora y beneficiaria de la situación originada por la conquista española adoptar la posición de víctimas al mismo nivel que los miembros de las culturas indígenas» (Constenla 2004, 12-13).

Pero lo nocivo de esta metáfora no es solo el proceso de ocultamiento o soslayo que opera sobre los principales rasgos culturales e históricos de los costarricenses y del país mismo (pues, hasta donde se sabe, ni bribris ni cabécares ni ningún otro pueblo indígena fundaron un país llamado «Costa Rica»), sino que también es nefasto los corolarios ideológicos de esta idea. Considerar a los indígenas como el «origen» o los «antepasados» de la nación no permite, de ninguna forma, superar las herencias del pensamiento colonialista europeo, el cual, como se sabe, veía en los pueblos originarios seres salvajes y primitivos (seres que vivían en un estadio histórico anterior).

La idea del «origen» remite, de forma invariable, a los principios o antecedentes de algo, los cuales deben ser necesariamente anteriores. Ello reafirma, como se dijo, la ideología europea de la conquista. En esencia, estamos ante una visión renovada que, en lugar de ver a los indígenas como «pueblos primitivos», los ve como «seres del pasado». Por eso, esta metáfora de amplia divulgación que establece que LOS INDÍGENAS SON NUESTRAS RAícES no hace otra cosa más que condenar a dichos pueblos a un mundo pretérito que nada tiene que ver con el actual. Esto no solo es absolutamente falso, sino que tiene consecuencias nefastas. Hay que tener claro que los indígenas, como los borucas, los bribris o los malécus, no son parte del pasado: son personas que viven en el presente. Son parte del mundo contemporáneo y coexisten con la población no indígena actual. Es absurdo suponer que uno puede ir a 
Talamanca a visitar «su pasado»o «sus ancestros», pues se trata de personas coetáneas, que sufren al igual que cualquier otra las vicisitudes de un presente cambiante y azaroso.

\section{La idea de la autenticidad originaria}

La tercera idea de fondo que gobierna la representación discursiva de los indígenas en los mensajes de Facebook, es una derivación o consecuencia de la metáfora anterior y se relaciona con el estatus de fidelidad que representan los indígenas con respecto a la construcción simbólica de la nación costarricense. En efecto, si como se dijo en el apartado anterior, los indígenas son la «raíz» (la fuente primigenia del «ser costarricense»), esto quiere decir que su vida, costumbres y modo de pensar tradicional constituyen una versión pura e incontaminada de la identidad nacional. A nivel del discurso, esto se traduce en indicar de forma constante que los indígenas son «auténticos»o «genuinos», tal y como puede apreciarse en la siguiente cita (véase Figura 7):

Los verdaderos ticos totalmente olvidados por todos Me gusta - Responder - 1 - 3 de marzo a las 17:33

Figura 7. Comentario emitido en Facebook Fuente: Captura de Facebook.

Nótese que la cita anterior, siempre en el marco de reproche típico de los mensajes de Facebook, busca recalcar la situación de injusticia vivida por estos pueblos mencionando que, dentro del colectivo nacional, ellos no deberían ser víctimas de atropellos, pues son los «verdaderos ticos», quienes detentan la nacionalidad genuina de Costa Rica. Es importante mencionar aquí que el discurso sobre los indígenas analizado no se caracteriza, en general, por ser un dechado de coherencia. En este caso en particular, no queda claro cómo los indígenas, siendo supuestamente el origen histórico de la identidad nacional, se diferencian del resto de la población por la conservación de un estilo de vida, valores o pensamiento más auténtico. ¿Qué fue lo que pasó? ¿El resto de la población sufrió un proceso de degeneración?

En realidad, los discursos no tienden a evaluar de forma exhaustiva su coherencia interna. Aquí, más bien, entran en juego los estereotipos que la ideología propaga con respecto a 
ciertas poblaciones. Los indígenas, por su supuesta conexión con el primitivismo, son más susceptibles de ser vistos de esta forma. Por eso no falta quien se moleste al ver a un indígena con corbata o utilizando un celular, pues esto implica que no cumple con sus expectativas estereotipadas sobre ellos.

En todo caso, lo relevante acá es ver cómo existen manifestaciones discursivas que ponderan la nacionalidad indígena sobre la de otro tipo de poblaciones. Hay, en este sentido, diversos grados de nacionalidad y los indígenas deberían, en opinión de muchos comentaristas de Facebook, ocupar el puesto más alto dentro de dicha escala. Las siguientes declaraciones son prueba de ello (véase Figura 8):

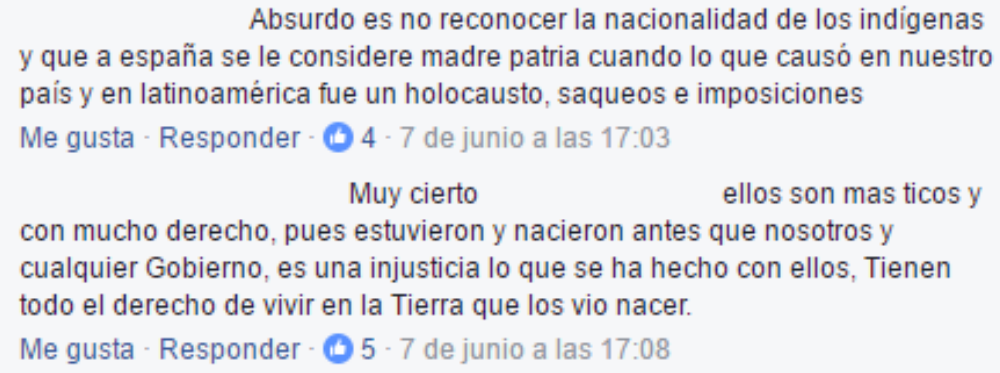

Figura 8. Comentarios emitidos en Facebook Fuente: Captura de Facebook.

Se aprecia que el primer enunciador se desliga totalmente de España y su proceso de conquista, lo cual le permite eludir toda la responsabilidad histórica, tal y como se explicó en la sección anterior. Es así como propone que la nacionalidad debe ser entendida en relación con la población indígena. El segundo enunciador, por su parte, termina recalcando que los indígenas «son mas ticos» (sin tilde en el original), pues su existencia es previa a la de su conjunto social. Está claro que hay una incoherencia en la propuesta que no es vista por los hablantes, pues no queda claro cuándo empezaron a existir los ticos. En este tipo de declaraciones, pareciera como si estos y el país fuesen atemporales, dado que ya los indígenas fueron «los primeros ticos» y los españoles vinieron a maltratar el país (en realidad, hay que tener en cuenta que lo fundaron en tanto entidad jurídica).

\section{(c) ) BY-NC-ND}

Esta obra está bajo una Licencia Creative Commons Atribución-NoComercial-SinDerivadas 4.0 Internacional. 
Esta idea del indígena como portador de autenticidad no es nueva y constituye, con toda probabilidad, una derivación del discurso creado sobre los aborígenes tras la conquista de América, el cual se explicará más adelante. De hecho, Carlos Sánchez ha abordado el tema de las ideologías lingüísticas en Costa Rica e identifica la presencia de este discurso de la autenticad indígena en diversas obras textuales desde la década de los setenta, así como también las contradicciones inherentes a dicha formulación: «la ideología en boga en los últimos años plantea que los pueblos indígenas, al descender de las poblaciones originarias del territorio, son los "verdaderos" o "auténticos" costarricenses, de modo que sus prácticas culturales son también las más auténticas y, por lo tanto, conforman la identidad "original" del costarricense» (Sánchez Avendaño 2013, 210).

Desde un punto de vista crítico, cabe hacer algunas apreciaciones sobre esta idea. En primer lugar, es evidente que ningún pueblo indígena creó una nación llamada «Costa Rica». Costa Rica, al igual que los demás países del continente, es el producto de la colonialidad europea y sus instituciones legales. Los colonizadores, al llegar a estas tierras, crearon, en primer lugar, una provincia jurídicamente dependiente de España, la cual se independizó luego creando el país que actualmente existe. Por otro parte, la nacionalidad costarricense es, como han demostrado diversos estudios, una construcción de la élite oligárquica, cafetalera y vallecentraleña de finales del S. XIX en Costa Rica. Fueron ellos los que inventan la nacionalidad en tanto fenómeno simbólico y discursivo.

Dicho esto, ¿cómo pueden ser los indígenas los detentadores más auténticos de una identidad nacional y un simbolismo patrio que ellos mismos no crearon? En realidad, estamos en presencia de una quimera creada mediante el discurso cuya finalidad no es la afirmación de los pueblos indígenas nacionales, sino la justificación, a nivel ideológico, de un sistema axiológico y un simbolismo específicos. No es de extrañar, entonces, que los indígenas tiendan a ver tales construcciones como extrañas, como bien lo recuerda Martínez Hoyos (2018, 150): «a los indígenas les costará sentir como propias sus teóricas nacionales. De ahí que la guatemalteca Rigoberta Menchú explicara que su pueblo no celebra el día de la independencia, acontecimiento histórico que le parece ajeno. Porque, para las comunidades originarias, la separación de España no habría significado una liberación». 


\section{El paradigma del «indio ecológico»}

El último núcleo de sentido que gobierna la manera de entender al indígena en las redes sociales costarricenses, es uno de los estereotipos más comunes relacionados con ellos, el cual constituye además una herencia directa de la visión que los europeos impusieron sobre dichas poblaciones a su llegada a América. Se trata de la idea de que los aborígenes viven en armonía con la naturaleza, imagen persistente y cuya formulación puede apreciarse en la siguiente cita (Figura 9):

23 de abril

Super agradecido aprender y enseñar a mis hijos la cultura el respeto a la naturaleza y legado de nuestra antepasados gracias.

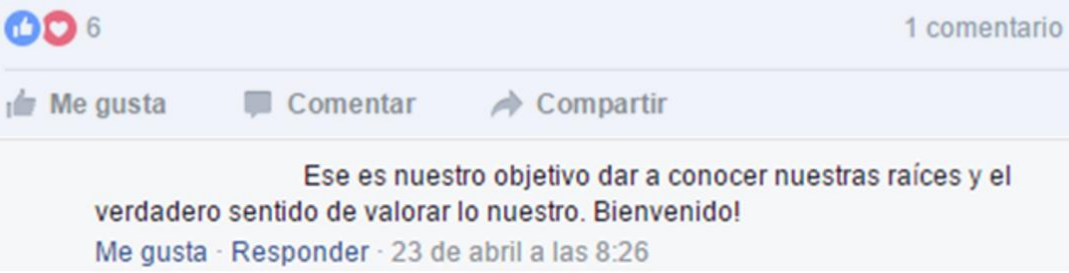

Figura 9. Comentarios emitidos en Facebook Fuente: Captura de Facebook.

Como se ve, el enunciador estima que los indígenas son una fuente de «respeto a la naturaleza» que debe ser emulada. Se está en presencia aquí del paradigma del «indio ecológico» identificado por Bolaños y González (2010) en su estudio sobre la representación de los pueblos indígenas costarricenses en las producciones audiovisuales. En dicho trabajo, se explica que uno de los estereotipos más comunes del país es considerar al indígena como un modelo de la vida ecológica y sostenible, pues la corrupción del ser humano se debe al contacto con el «mundo moderno o civilizado», del que los indígenas no forman parte según el discurso dominante (recuérdese su conexión simbólica con las ideas de primitivismo y barbarie). No cabe la menor duda de que este tipo de consideraciones se inscribe en la construcción europea del «buen salvaje», imagen romántica del indígena y popularizada desde la época de la conquista, la cual, a su vez tiene su origen en la conocidísima y

\section{(cc) EY-NC-ND}

Esta obra está bajo una Licencia Creative Commons Atribución-NoComercial-SinDerivadas 4.0 Internacional. 
antiquísima dicotomía civilización/barbarie ${ }^{11}$. Lo que sucede en este caso, es que, en palabras de estos autores, se ha trastocado la escala de valores imperante:

En la lógica del conquistador, el indígena era el «salvaje» y el europeo, cuyo correlato en nuestro medio es el «blanco», cumplía el papel de agente civilizador. Uno se concebía de forma negativa y el otro de forma positiva.

Hoy día, la dicotomía subyacente al proceso ideológico es la misma, solo que se han invertido los términos y la que es considerada una cultura nociva es la europea. [...] El indígena continúa siendo visto como el otro que guarda una relación armoniosa con la naturaleza, como alguien que vive de forma «natural», lo que sucede es que esto ya no se ve de forma peyorativa, ya no es el «salvaje» que debe ser civilizado, sino el «ecológico», que debe ser imitado por su armonioso estilo de vida. (Bolaños y González 2010, 63).

Desborda las pretensiones de este trabajo hacer un examen exhaustivo de las implicaciones nocivas derivadas de estas ideas que defienden al indígena como un modelo ecologista que debe ser imitado. En todo caso, hay un muy pertinente ensayo crítico al respecto elaborado por Morán Varela (2008) que disecciona, con detalle, gran parte de sus problemas: la no superación de la herencia histórica colonialista que le dio origen; la aplicación de políticas que, en lugar de buscar el desarrollo integral de estos pueblos, los aviene a mantener su situación de subdesarrollo; el uso del intervencionismo estatal o institucional para apoderarse de su conocimiento ancestral; la «museificación» de su cultura y, sobre todo, la imposición de una identidad y simbolismo indígenas creados desde fuera de su preocupaciones y vivencias.

\section{Conclusiones}

A partir de todo lo anterior, se torna bastante claro que los comentarios vertidos en Facebook sobre noticias relacionadas con indígenas evidencian que, en efecto, hay una integración a nivel del discurso de esta población dentro del imaginario de la identidad costarricense. Esta inclusión se materializa, sobre todo, en las cuatro ideas antes analizadas:

\footnotetext{
11 Al respecto, considérense las palabras de Martínez Hoyos (2018, 42): «La visión occidental del indígena vendrá marcada por dos estereotipos. El más popular, el del buen salvaje. Los cronistas hispanos, como antes sus predecesores latinos, remarcan la nobleza del carácter de los "bárbaros”».
} 
los indígenas son un grupo genérico entendido como parte de la sociedad costarricense que los asume y determina a través del uso del pronombre «nuestro»; conforman el origen o antecedentes de la población del país y, por ello, son los más auténticos detentadores de sus principales valores, aun y cuando se distinguen por vivir en un estado de armonía con la naturaleza. Sin embargo, estas cuatro ideas generales, que determinan la representación discursiva del indígena en los mensajes recopilados son, en esencia, herencias simbólicas de la ideología europea colonizadora que creó la categoría misma de «indígena» y guardan, por lo tanto, los defectos de una visión simplista y cargada de estereotipos. Se impone, a futuro, un replanteamiento de la manera como la población hegemónica costarricense concibe y se refiere a dichos pueblos.

Apoyo financiero: Universidad de Costa Rica.

\section{Referencias}

Acuña Ortega, Víctor Hugo. 2002. «La invención de la diferencia costarricense». Revista de Historia, 45: 191-228.

Baker, Paul y Anthony McEnery, eds. 2015. Corpora and Discourse Studies: Integrating Discourse and Corpora. Nueva York: Palgrave Macmillan.

Bolaños Esquivel, Bernardo y Guillermo González Campos. 2010. Las miradas con que vemos: Análisis de la representación audiovisual de los pueblos indígenas de Costa Rica San José: Universidad de Costa Rica, Vicerrectoría de Acción Social.

Cabal Antillón, Dionisio. 2008. «'Costarrica’, nombre indígena». La Nación, Suplemento Áncora, 11 de mayo. Recuperado de http://wvw.nacion.com/ancora/2008/mayo/11/ancora1528920.html

Cabal Antillón, Dionisio. 2016. «El origen de «jupe!». Caminante del Sur, 27 de diciembre. Recuperado de https://caminantedelsur.com/2016/12/28/el-origen-de-upe-por-dionisiocabal-antillon/

Camacho Nassar, Carlos. 1998. «Las paradojas de la identidad indígena: ideologías y realidades en Costa Rica». En María Eugenia Bozzoli y otros. (comps.). Primer Congreso Científico sobre Pueblos Indígenas de. Costa Rica: Memoria. San José: EUNED.

Charaudeau, Patrick y Dominique Maingueneau. 2005. Diccionario de análisis del discurso. Buenos Aires: Amorrortu.

\section{(cc) BY-NC-ND}

Esta obra está bajo una Licencia Creative Commons Atribución-NoComercial-SinDerivadas 4.0 Internacional. 
Constenla Umaña, Adolfo. 2004. «Migraciones e identidad cultural en Costa Rica: examen de la tesis de la identidad cultural mestiza». Ponencia presentada en el III Congreso Internacional de la Lengua Española: Identidad lingüística y globalización. Rosario, Argentina.

de la Cadena, Marisol y Starn, Orin. 2009. «Indigeneidad: problemáticas, experiencias y agendas en el nuevo milenio». Tabula Rasa, 10: 191-223.

Díaz Arias, David. 2004. La construcción de la nación: teoría e historia. San José: EUCR.

Fairclough, Norman. 1992. Discourse and Social Change. Cambridge: Polity Press.

Giglioli, Giovanna. 1996. «iMito o idiosincrasia? Un análisis crítico de la literatura sobre el carácter nacional». En Identidades y producciones culturales en América Latina. San José: EUCR.

Jiménez, Alexander. 2005. El imposible país de los filósofos: el discurso filosófico y la invención de Costa Rica. Segunda edición. San José: EUCR.

Lakoff, George y Mark Johnson. 1991. Metáforas de la vida cotidiana. Madrid: Cátedra.

Mancera Rueda, Ana y Ana Pano Alamán (2014): «Las redes sociales como corpus de estudio para el Análisis del discurso mediado por ordenador». Janus, Anexo 1: 305-315.

Martínez Hoyos, Francisco. 2018. El indigenismo: desde 1492 hasta la actualidad. Madrid: Cátedra.

Matus, Pablo. 2015. «Hacia una teoría de la representación discursiva». Ponencia presentada en el IX Congreso Internacional Chileno de Semiótica. Pucón, Chile.

Morán Varela, José Antonio. 2008. «La construcción occidental de los mitos sobre el indígena». Pukara: Cultura, sociedad y política de los pueblos originarios de Bolivia, 3(27): 6-8.

Ovares, Flora, Margarita Rojas, Carlos Santander y María Elena Carballo. 1993. La casa paterna. San José: EUCR.

Pacheco Hernández, Daniel. 2013. «La identidad costarricense ante los dilemas de la migración, diversidad cultural y desigualdad económica». Revista Reflexiones, 92(2): 23-33.

Palmer, Steven. 1996. «Racismo intelectual en Costa Rica y Guatemala, 1870-1920». Mesoamérica, 31: 99-121.

Parodi, Giovanni. 2010. Lingüística de Corpus: de la teoría a la empiria. Madrid: Iberoamericana.

Quesada Pacheco, Miguel Ángel. 2017. «¿Son 'Costa Rica' y 'upe' de origen huetar?». La Nación, Suplemento Viva, 19 de marzo. Recuperado de https://www.nacion.com/viva/cultura/son-costa-rica-y-upe-de-origenhuetar/3QP23MXN2RFEJAKDTIATL3E5UE/story/

Quesada Soto, Álvaro. 1998. Uno y los otros. San José: EUCR. 
Sánchez Avendaño, Carlos. 2013. ««Ticos auténticos ... que no hablan español»: ideologías sobre las lenguas minoritarias y la diversidad lingüística de Costa Rica». Revista de Filología y Lingüística de La Universidad de Costa Rica, 39(2): 191-218.

Soto Quirós, Ronald. 1998. ««Desaparecidos de la Nación»: los indígenas en la construcción de la identidad nacional costarricense 1851-1924». Revista de Ciencias Sociales, 82: 31-53.

Van Dijk, Teun A., comp. 2000a. El discurso como estructura y proceso. Barcelona: Gedisa. Van Dijk, Teun A., comp. 2000b. El discurso como interacción social. Barcelona: Gedisa. 